\title{
Predictive performance models in the South African Business Process Services industry
}

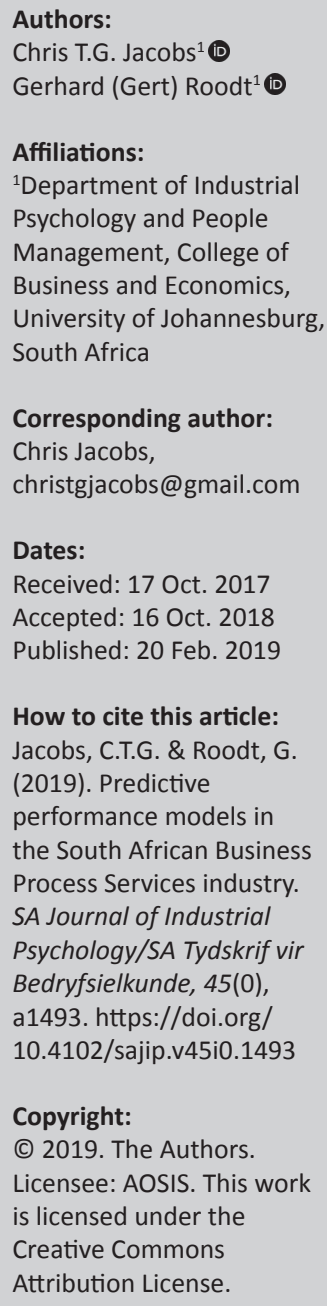

Orientation: An earlier systematic literature review study (Jacobs \& Roodt, 2011) conducted on research in Business Process Services (BPS) industry sector companies identified a number of variables that could be empirically linked to turnover intention and individual performance. The literature pointed to a potential health promotion process, as well as an individual performance process in the BPS environment.

Research purpose: The purpose of this study is to test two different predictive models that may explain two distal outcomes, namely turnover intention and individual employee performance, in the South African (SA) BPS industry.

Motivation for the study: There is little, if any, peer-reviewed, empirical research available on the BPS industry that links variables to either proximate or distal outcome variables, such as turnover intention and individual employee performance.

Research approach/design and method: A two-stage, census-based sampling approach was followed that initially targeted 40 organisations within the industry that employ about 13000 employees. Sixteen of these organisations (employing about 6800 individuals) indicated that they wish to voluntarily participate in the study; 821 individuals were targeted to participate in the cross-sectional survey and 487 usable responses were obtained (a 59\% response rate). Multivariate data analyses were conducted from an exploratory perspective to retrospectively explain relationships in the structural models.

Main findings: An overall health promotion process model that predicted the distal outcome, turnover intention, was confirmed within the context of this exploratory study, where human resource management (HRM) practices, job demands (JDs) and job resources (JRs) were related to burnout as the only proximate outcome. On the other hand, an individual performance enhancing process model was also confirmed within the context of this exploratory study by using HRM practices, JRs and JDs, together with proximate variables, such as employee competence and engagement, to explain the distal outcome, individual performance.

Practical/managerial implications: The study has implications for executive (strategic) management, human resource (HR) professionals and work unit team leaders in the BPS industry. This study shows which JRs contribute towards the reduction of burnout and turnover intention in the BPS context. On the other hand, it explains how HRM practices, as well as JRs and JDs, in combination with employee competence and engagement, can be used to promote individual performance.

Contribution/value-add: This is the first SA study that uses a range of variables in a multivariate analysis to predict turnover intention and individual performance in the SA BPS industry.

\section{Introduction}

Business Process Services (BPS) is an umbrella term that describes an industry sector that includes a number of different types of business activities, such as contact centre services (CCS) - or more commonly known as call centres, information technology outsourcing (ITO), knowledge process outsourcing (KPO) and shared service centres (SSCs) (Frost \& Sullivan Consulting, 2009). In South Africa, the BPS industry is a relatively new sector (Dimension Data, 2008) and is focused on performing '... a business process activity either in full or in part' (Engman, 2007, p. 8).

In the BPS industry, the increase of adverse consequences, such as decreased customer satisfaction levels, lower contact resolution rates, higher employee attrition and absenteeism has been noted (Dimension Data, 2008, 2014). These trends are indicative of the need for a better predictive ability 
at managing human capital in BPS environments (Fitz-Enz, 2009). Drivers of the aforementioned consequences are often quoted to be a work environment of a more technological, product- and information-overload nature. Customer expectations demand increasingly more complex business transactions across omni-communication channels with a resulting emphasis on higher employee skill sets requirements (Aksin, Armony, \& Mehrotra, 2007). Extreme work pressures and overly controlled and monitored work environments resulted in these environments often being labelled as ideally suited for 'panopticon control' (Banks \& Roodt, 2011).

Against this backdrop, Jacobs and Roodt (2011) conducted a systematic literature review in order to identify variables that were empirically related to BPS performance. The literature pointed to a potential health promotion process, as well as an individual performance process. Eight human capital predictive constructs were identified that empirically related to turnover intention and/or employee performance. These key constructs are human resource management practices, job demands (JDs), job resources (JRs), employee competence, employee engagement, person-environment fit (P-E fit), employee well-being and burnout. To date, no South African (SA) study could be found that integrated these variables into a comprehensive (multivariate), predictive, empiricallytested model.

The main objective of the study will therefore be to investigate a human capital predictive model of turnover intention and employee performance in the BPS industry. The two research objectives flossing for the main objective are:

- to establish if HRM practices, JRs and JDs, in combination with proximate variables (well-being, burnout and engagement), predict the distal outcome, turnover intention

- to establish if HRM practices, JRs and JDs, in combination with proximate variables (P-E fit, employee competence and engagement), predict the distal outcome, individual performance.

The importance and relevance of the study are twofold: Firstly, it will identify which variables contribute independently or interactively to proximate outcomes (such as engagement, burnout, well-being, P-E fit and employee competence) and distal outcomes (such as turnover intention or individual performance). Secondly, it will enable executive management, HR managers and unit managers to use this information to effectively manage and improve individual performance in this industry sector.

\section{Theoretical orientation and literature review}

\section{Theoretical orientation}

The theoretical framework, in which this study will be embedded, is the General Systems Theory (GST), because it encapsulates the information age worldview (Dostal, Cloete, \& Járos, 2005), as well as the force field analysis (Lewin, 1951). Jacobs and Roodt's (2011) systematic literature review pointed to the fact that HRM practices are related to JRs, which in turn predicted engagement, burnout and wellbeing. Job demands are related to engagement, burnout and well-being. Engagement, burnout and well-being predicted turnover intention. Similarly, Jacobs and Roodt's (2011) systematic literature review also pointed to the fact that HRM practices are related to JRs, which in turn predicted employee competence and engagement. Job demands and $\mathrm{P}-\mathrm{E}$ fit are related negatively to engagement. Engagement and employee competence predicted performance. These literature review findings suggest the existence of two models, namely a positive individual-performance outcome model and a health-demotion outcome model. Thus, Jacobs and Roodt's (2011) systematic literature review identified human capital predictive constructs that were empirically related to turnover intention and/or employee performance. These models have similar features as a system: an organised whole that is characterised by co-production of human capital constructs, emergence because of the interaction of these constructs that affect new properties that are not inherit in the individual parts, incorporating circular causation and mutual impact (Dostal et al., 2005). GST endeavours to understand the complexity of design systems that produce desirable synergies and therefore constitute an approach for the design and management of work (Jaaron \& Backhouse, 2010), which is particularly relevant to the BPS industry. GST allows specifically testing for the interactions and interrelationships of variables on different levels. Schaufeli and Taris (2014) caution that variables should be assessed on the same level as the unit of analysis used in a study (e.g. individuals as is the case in this study).

\section{Literature review}

In the section below, each of the constructs used in the study and its relationship with other variables in the model will be briefly described. The variables are grouped into three broad categories, namely contextual variables, proximate outcomes and distal outcomes:

\section{Contextual variables}

Human resource management (HRM) practices: The term human resources emphasises employees as organisational resources or assets (Liu, Combs, Ketchen, \& Ireland, 2007). Jacobs and Roodt (2011) incorporated Liu et al.'s (2007) three HRM categories (competence, commitment and context) that entail nine practices (selection, compensation level, training, incentive compensation, internal promotion, participation programmes, flexitime, grievance procedures and employment security) into the model, as these optimally impact organisational performance. Liu et al.'s (2007) model provides a well-substantiated taxonomy of HRM practices in the context of the organisation and is based on a metaanalysis of 92 scientific investigations that included data from over 19000 organisations. Liu et al.'s (2007) model is therefore an ideal model to use in the BPS environment, as it provides a framework for investigating the effects of HRM practices on performance at an organisational level, a team level and an individual level (Robbins, Judge, Odendaal, \& 
Roodt, 2009). The three key broad HRM practices groupings that impact performance at an organisational level (Liu et al., 2007) are discussed next:

- Competence-related practices: Social competencies (such as communication skills and people skills) are critical to employee performance in BPS (Belt, Richardson, \& Webster, 2002). Selection and technical competence and product knowledge training are therefore critical (Callaghan \& Thompson, 2002; Van Den Broek, 2003). Cross-training in two areas of proficiency per employee enhances performance and influences employee satisfaction (Aksin et al., 2007; Malhotra, Budhwar, \& Prowse, 2007).

- Commitment-related practices: Commitment levels improve when using both measureable and qualitative individual performance incentives (Aksin et al., 2007). Motivation to achieve personal objectives is enhanced by applicable extrinsic incentives (Rose \& Wright, 2005), with incentive schemes assisting in retaining employees (Robinson, 2006). Pay-for-performance remuneration initiatives are common in sales-orientated BPS environments (Batt, Holman, \& Holtgrewe, 2009). Career promotion and succession are limited in BPS sectors (Batt, 2002; Gorjup, Valverde, \& Ryan, 2008), although internal advancement is supported, because of their influence on commitment levels and the tedium of the job content (Carrim, Basson, \& Coetzee, 2006).

- Context-related practices: Participation programmes, flexitime and grievance procedures positively impact retention (Batt, 2002; Cox, Griffiths, \& Rial-González, 2000). Long-term employment reassurance is essential for commitment (Batt, 2002; Zapf, Isic, Bechtoldt, \& Blau, 2003).

In view of the above, it is hypothesised that HRM practices create the foundation for establishing the much needed JRs to counteract JDs within the work context in order to promote individuals' job performance.

The Job Demands-Resources (JD-R) Model (Bakker \& Demerouti, 2016; Demerouti \& Bakker, 2011) is an empirical model that elucidates how JRs produce engagement (and employee retention) and wellness issues (starting with a lack of energy, which could eventually lead to health problems) are expedited by JDs, as defined by Bakker, Demerouti, and Schaufeli (2003) and Dwyer and Fox (2006). JDs are related negatively to individual performance, and JRs act as moderators (or buffers) (Dwyer \& Fox, 2006). Absenteeism will decrease when JRs increase, which will positively impact employee performance (Bakker et al., 2003; Swart, 2006). JRs increase engagement through an increase in energy, involvement and efficacy, which will enhance individual performance (Demerouti, Bakker, Nachreiner, \& Schaufeli, 2001). The interaction between JDs and JRs, as well as their respective relationships with HRM practices, with the ultimate impact on individual performance, is unknown in a multivariate model in the BPS context. These relationships will be hypothesised and tested in the proposed study:
- Job demands are defined as '... initiators of a health impairment process' (Demerouti \& Bakker, 2011, p. 1). JDs are not aggravators, but may turn into stressors when sustained elevated effort is required to meet work-related demands, and when health recovery is inhibited (Demerouti \& Bakker, 2011). Critical JDs (as identified by Bakker et al., 2003; Dwyer \& Fox, 2006) included changes in tasks, work pace demands and workload. JDs such as role demands, emotional demands and technological demands (e.g. computer problems) were excluded from the measuring scale for parsimonious purposes.

- Job resources are defined as 'initiators of a motivational process' (Demerouti \& Bakker, 2011, p. 1) that can act as motivators, whereby JRs collectively (or socially) provide support, with individual performance feedback encouraging engagement, dedication and commitment to the organisation, resulting in retention of employees. It is assumed that JRs moderate (or buffer) JDs' effect on stress and burnout, with JRs moderating engagement when JDs are high (Demerouti \& Bakker, 2011). Critical JRs (as identified by Bakker et al., 2003; Dwyer \& Fox, 2006) included social support, as well as pay and benefits. JRs such as job characteristics, time control and individual performance feedback were excluded from the measuring scale for parsimonious purposes. Personal resources were also conceptualised as a critical resource alongside JRs (Bakker \& Demerouti, 2016) with reference to self-efficacy, organisation-based self-esteem and optimism (Demerouti \& Bakker, 2011).

It is argued that HRM practices in combination with JRs and JDs create the context in which employees perform their daily duties. This context can either facilitate or inhibit proximate outcomes.

\section{Proximate outcomes}

Employee competence is the combination of technical, social or behavioural knowledge, skills and abilities (KSAs); personality attributes; and principles that are essential in executing organisational duties (Grobbelaar, Roodt, \& Venter, 2004). Bagnara and Marti (2001, p. 227) summarised BPS knowledge workers' related core competency as '... understanding clients' requests and finding, accessing and manipulating knowledge in the organisation and in the cognitive artefacts', alongside having content knowledge, service knowledge and product knowledge.

Minimal competence effectiveness includes '... crossfunctional awareness, initiative, persuasiveness and understanding practices, ability to listen and to be attentive to detail and information' (as detailed by Jacobs \& Roodt, 2011, p. 9, based on Grobbelaar et al., 2004; White \& Roos, 2005). The ability to perceive the customer's perspective and expectations (Axtell, Parker, Holman, \& Totterdell, 2007; Burgers, De Ruyter, Keen, \& Streukens, 2000) constitutes social competence. Emotional intelligence (Higgs, 2004; Nel \& De Villiers, 2004) and personality features were reported to be contributors to individual performance (Moller, Crous, \& 
Schepers, 2004; Nicholls, 2006; Ojha \& Kasturi, 2005; Van der Linde, 2005). It is not known how employee competence interacts with JDs and JRs and HRM practices to impact employee performance in a multivariate model. These relationships will be hypothesised and tested in this study.

$P-E$ fit is defined as the employee-work environment congruency that manifests when the individual qualities are complementary to the work situation (Cox et al., 2000), where incongruity could result in stress (Le Fevre, 2003). The five aspects of P-E fit (Billsberry, Marsh, \& Moss-Jones, 2004) are as follows: (1) person-organisation (P-O) fit, where the employee's values match those of the organisation; (2) person-vocation $(\mathrm{P}-\mathrm{V})$ fit, which implies the employee's selfconcepts-occupation congruence; (3) person-job (P-J) fit, where the employee's KSAs and the occupation's requirements are aligned; (4) person-group (P-G) fit, a measure of the employee-team congruence; and (5) personpeople (P-P) fit, relating to congruence between the employee's culture and that of colleagues. It is known that the P-E fit dimension has an inverse relationship with turnover, with a limited impact on individual performance (Arthur, Bell, Doverspike, \& Villado, 2006; McCulloch \& Turban, 2007; Yang, Che, \& Spector, 2008). The P-J fit dimension also correlates with selection (an HRM practice) and the competence of employees (Werbel \& Gilliland, 1999). Some studies allude to the P-E fit and work engagement link through job crafting or the mediating role of the needssupply sub-dimension of P-J fit between job crafting, burnout and work engagement (Lu, Wang, Lu, Du, \& Bakker, 2014; Travaglian, Babic, \& Hansez, 2016). What is therefore not known is the relationship of P-E fit with employee engagement in conjunction with employee competence, in affecting the overall individual performance in a multivariate model. This relationship will be hypothesised and tested in the proposed study.

Employee engagement: Schaufeli and Bakker (2010, p. 13) defined and operationalised work engagement as '... a positive, fulfilling, work-related state of mind that is characterised by vigour, dedication, and absorption'. In the words of Saks (2006, p. 602), it is the degree to which an individual is attentive and absorbed in the performance of their roles'. Engagement is characterised by high energy, high involvement and high efficacy, while burnout (the inverse of engagement) is characterised by exhaustion, low energy, cynicism and inefficacy (Simpson, 2008). It is not known how employee engagement interacts with employee competence and P-E fit in the prediction of employee performance. This relationship will be investigated more closely.

Employee well-being is defined as 'a state of complete physical, mental and social well-being and not merely the absence of disease or infirmity' (World Health Organisation (WHO), 2006, p. 1). Mental well-being is defined by the WHO as:

... a state of well-being in which every individual realises his or her own potential, can cope with the normal stresses of life, can work productively and fruitfully, and is able to make a contribution to her or his community. (World Health Organisation, 2006, p. 1)
Negative aspects, inclusive of actual illness, and positive aspects, such as contentment, are implied in the definition. Fatigue contributes directly to burnout and the intention to leave, with fatigue-related antecedents lowering employees' work contentment (Campbell, 2003; Visser \& Rothmann, 2008, 2009). Job-related demands explain health issues, work contentment positively correlates with organisational climate, and shoulder and/or arm musculoskeletal distress indicates physical work distress (Bakker et al., 2003; Dladla, 2009; Dwyer \& Fox, 2006; Kerstin, 2005). The impact of employee well-being on individual performance in a multivariate model is not known; this relationship will be hypothesised and tested in the proposed study.

\section{Burnout is defined as:}

\begin{abstract}
... a persistent, negative, work-related state of mind in 'normal' individuals that is primarily characterised by exhaustion, which is accompanied by distress, a sense of reduced effectiveness, decreased motivation, and the development of dysfunctional attitudes and behaviours at work. (Schaufeli \& Enzmann, 1998, p. 36)
\end{abstract}

Literature that supported the hypothesis specific to this article included the following: Job demands expedite burnout in the context of the heuristic JD-R Model (Bakker et al., 2003; Dwyer \& Fox, 2006). Work burnout is the reduced health or energy processes related to job demands (Demerouti \& Bakker, 2011). It has been postulated that job resources moderate (or buffer) job demands' effect on stress and burnout (Demerouti \& Bakker, 2011).

It is argued that the contextual factors in combination with the proximate outcomes (well-being, burnout, P-E fit, employee competence and engagement) will contribute towards distal outcomes, such as turnover intention or employee performance. Two suppositions support this notion: The first supposition is that a negatively perceived context may lead to ill-being and burnout, which in turn may result in turnover. The second supposition is that a positively perceived context may result in greater P-E fit, improved employee competence self-assessments and increased engagement levels. This in turn will result in improved employee performance.

\section{Distal outcomes}

Turnover intention is the intent to resign from current employment (Spies, 2006). For the purpose of this study, the definition of Tett and Meyer (1993, p. 262) is used, who defined turnover intention as '... the conscious and deliberate willfulness to leave the organisation'. Burnout (or emotional exhaustion) is positively linked to turnover intention (Spies, 2006). Quit rates are lower when HRM practices such as high relative pay and employment security are present (Batt, 2002). It is not known how HRM practices, JDs, JRs, wellbeing, burnout and engagement impact turnover intention in a multivariate model; these relationships will be hypothesised and tested in the proposed study. 
Employee performance is defined by the South African Bureau of Standards (2008, p. 24) as '... individual performance to established targets and performance standards'. Normally, the management of performance concentrates on the employee at an individual level; however, performance at an organisation level should also be considered (Strydom, 2005). Intrinsic motivational levels support operational efficacy (Mahesh \& Kasturi, 2006). Work experience (i.e. prior competence) contributes positively to performance (Whitt, 2006), more so than the mere supervision of the individual performance metrics (Du Preez, 2008; Witham, 2009). It is not known how HRM practices, JDs, JRs, P-E fit, engagement and competence impact performance in a multivariate model; these relationships will be hypothesised and tested in the proposed study:

H1: Perceived HRM practices, JDs and JRs are individually or interactively predictors of proximate outcomes - well-being, burnout and engagement.

H2: Perceived HRM practices, JDs and JRs are individually or interactively predictors of proximate outcomes - employee competence and work engagement.

H3: Perceived contextual factors, as well as proximate outcomes of well-being, burnout and engagement, are related to turnover intention.
H4: Perceived contextual factors, as well as proximate outcomes P-E fit, employee competence and work engagement, are related to individual performance.

Against the background of the four hypotheses, two specified models (namely a turnover intention model and an individual performance model) will be tested in this study and they are graphically displayed in Figures 1 and 2.

\section{Research design Research approach}

The research design of this exploratory study followed the quantitative research tradition and used a cross-sectional, census-based survey design. Multivariate statistical techniques were used to analyse the data and to establish and explain relationships in an ex post facto manner. Individuals are the unit of analysis in this study and the selected variables are all assessed on the same level.

\section{Research method}

The research method followed in this study will be discussed under the following four sub-headings.

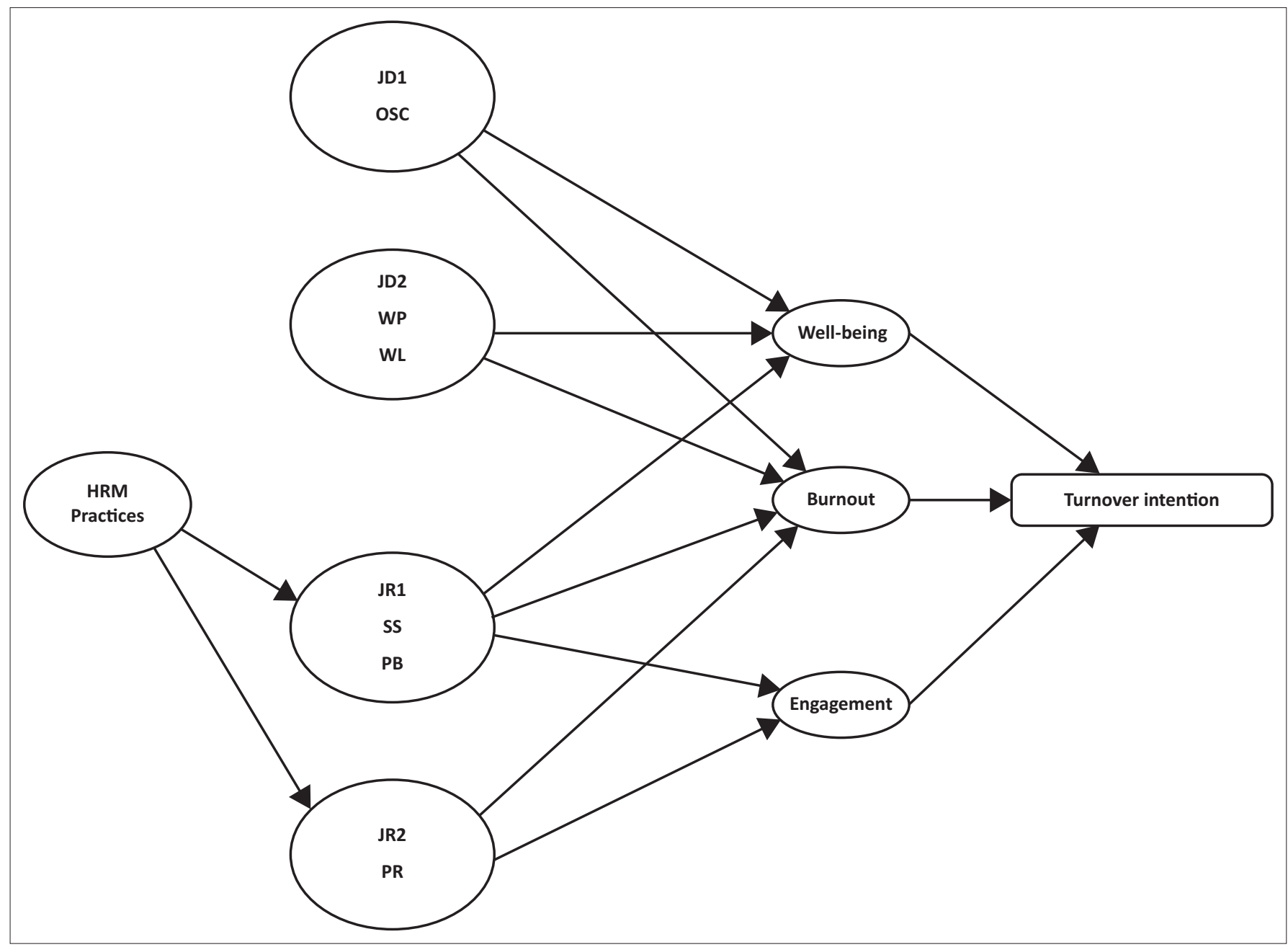

JD, job demands; OSC, organisational systems change; WP, work pace; WL, workload; JR, job resources; SS, social support; PB, pay and benefits; and PR, personal resources. FIGURE 1: Specified Model 1 - Predictors of turnover intention. 


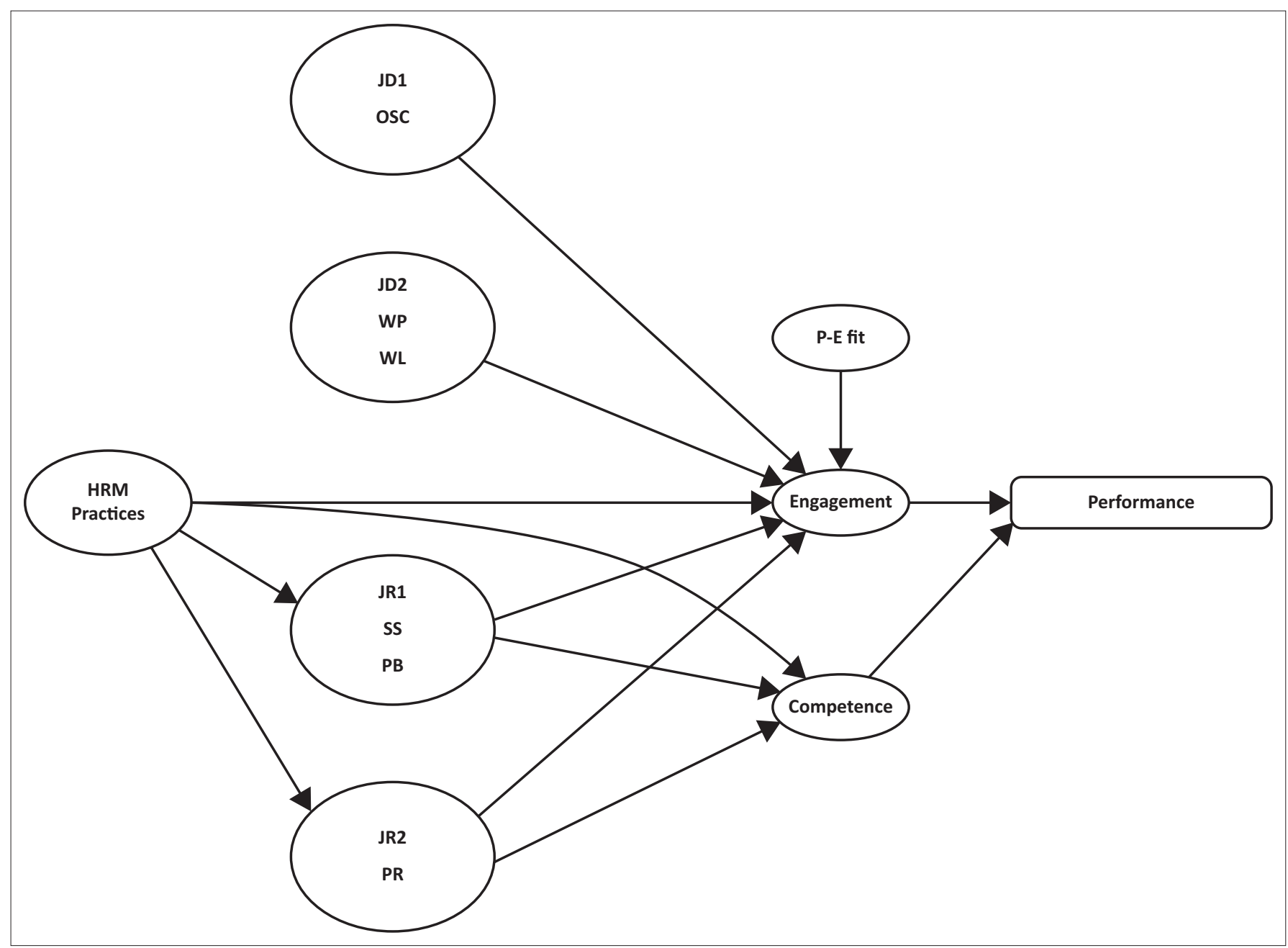

JD, job demands; OSC, organisational systems change; WP, work pace; WL, workload; JR, job resources; SS, social support; PB, pay and benefits; PR, personal resources. FIGURE 2: Specified Model 2 - Predictors of individual performance.

\section{Research participants and sampling}

A multistage census-based sampling approach was followed for purposes of this study, at two levels, namely the organisation and the individual employee. The target population of this study was employees who were employed in BPS organisations in South Africa. Jones (2008) reported that approximately 1500 BPS centres employed between 150000 and 175000 employees in 2008 in South Africa. Koyana (2010) estimated the number of employees at 200000 in 2010. Of these estimated numbers, the researcher approached approximately 40 organisations employing a total of 13000 BPS employees, which constituted the target population for this study. At the organisation level, 16 of the 40 organisations that indicated to participate (that employed approximately 6800 employees) with a $40 \%$ response rate. At the individual employee level, the final sample consisted of 487 respondents (487 out of 821 surveys distributed) with a $59 \%$ response rate.

It is evident from Table 1 that $69.9 \%$ of the sample was female, $59.4 \%$ was aged between 21 and 30 years, followed by $25.4 \%$ aged between 31 and 40 years; $62.4 \%$ of the sample was unmarried, while $35.3 \%$ of the sample's home language was an African language, followed by $30.6 \%$ who indicated
English as their home language. A total of $51.4 \%$ of the sample was African people, followed by $24.1 \%$ of mixed race people, and $42 \%$ of the sample had a tenure between 2 and 5 years.

\section{Measuring instruments}

The measuring instruments used in the study were based on the following conceptualisations of the constructs (summarised in Table 2):

HRM practices: The instrument focuses predominately on HRM practices as perceived by the employees. The construct is based on Liu et al.'s (2007) study and consists of three categories, with nine practices in total: (1) Competence, which includes Selection, Compensation level and Training as constructs; (2) Commitment, which includes Incentive compensation and Internal promotion as constructs; and (3) Context, which includes Participation programmes, Flexitime, Grievance procedures and Employment security as constructs. This measure consists of 17 items and was developed by Jacobs (2014), with the construct validity and reliability therefore previously unknown. An item example, rated on a seven-point intensity response scale with the extremes poles anchored, reads: 'How supportive is the company's recruitment strategy in establishing a competent workforce?' 
TABLE 1: Biographic and demographic details of the sample.

\begin{tabular}{|c|c|c|c|}
\hline Variable & Category & Frequency & Valid percentage \\
\hline \multirow[t]{4}{*}{ Gender } & Male & 142 & 30.1 \\
\hline & Female & 329 & 69.9 \\
\hline & Missing & 16 & - \\
\hline & Total & 487 & 100 \\
\hline \multirow[t]{7}{*}{ Age } & $<20$ & 25 & 5.9 \\
\hline & $21-30$ & 250 & 59.4 \\
\hline & $31-40$ & 107 & 25.4 \\
\hline & $41-50$ & 31 & 7.3 \\
\hline & $>51$ & 8 & 1.9 \\
\hline & Missing & 66 & - \\
\hline & Total & 487 & 100 \\
\hline \multirow[t]{6}{*}{ Education } & Lower than Grade 12 & 15 & 3.2 \\
\hline & Grade 12 & 244 & 51.9 \\
\hline & First degree or diploma & 164 & 34.9 \\
\hline & Hons, Master's or doctor & 47 & 10 \\
\hline & Missing & 17 & - \\
\hline & Total & 487 & 100 \\
\hline \multirow[t]{6}{*}{ Marital status } & Unmarried & 293 & 62.4 \\
\hline & Married or cohabitating & 149 & 31.7 \\
\hline & Divorced & 25 & 5.3 \\
\hline & Widowed & 3 & 0.6 \\
\hline & Missing & 17 & - \\
\hline & Total & 487 & 100 \\
\hline \multirow[t]{6}{*}{ Language } & Afrikaans & 99 & 21.1 \\
\hline & English & 144 & 30.6 \\
\hline & African Language & 166 & 35.3 \\
\hline & Other & 61 & 13 \\
\hline & Missing & 17 & - \\
\hline & Total & 487 & 100 \\
\hline \multirow[t]{6}{*}{ Race } & African & 239 & 51.4 \\
\hline & White & 87 & 18.7 \\
\hline & Mixed race & 112 & 24.1 \\
\hline & Indian or Asian & 27 & 5.8 \\
\hline & Missing & 22 & - \\
\hline & Total & 487 & 100 \\
\hline \multirow[t]{6}{*}{ Tenure } & $<1$ & 152 & 36.8 \\
\hline & $2-5$ & 176 & 42.6 \\
\hline & $6-9$ & 59 & 14.3 \\
\hline & $>10$ & 26 & 6.3 \\
\hline & Missing & 74 & - \\
\hline & Total & 487 & 100 \\
\hline
\end{tabular}

An indication of 1: Not supportive on the scale represents low intensity, and 7: Highly supportive represents high intensity.

Job demands: Changes in processes, procedures and tasks (at an organisational systems level, which filter down to demands at an individual level) are driven by continuous increases in complexity, because of customer demands and operational efficiencies. Work pace demands (at group level) reiterate the organisation's drive towards operational efficiencies. Workload represents the emphasis on organisational effectiveness and efficiency, at an individual-level demand (Bakker et al., 2003; Dwyer \& Fox, 2006; Rothmann, Mostert, \& Strydom, 2006; Swart, 2006). The various items from different authors were utilised based on applicability to the BPS environment. This measure included 12 items to capture the different JDs. An example is Item 28: 'How often do changes in your tasks pose difficulties to you?' The response scale range from 1: Never (indicating low intensity) to 7: Always (indicating high intensity). Rothmann et al. (2006) reported on reliability for the South African scale they had developed with Cronbach's alpha coefficients ranging from 0.76 to 0.92 . Construct validity was confirmed for two dimensions of JDs (overload and job insecurity).

Job resources: An important resource is social support (at group level) because of emotional labour. At the individual level, pay and benefits, as well as personal resources, act as individual performance enablers (Bakker et al., 2003; Dwyer \& Fox, 2006; Rothmann et al., 2006; Swart, 2006). Nineteen items were used to capture the different JRs in this study. An example reads: 'How often can you ask your colleagues for help if you have too much work?', with Never (indicating low intensity) and Always (indicating high intensity) being the anchors. Rothmann et al. (2006) noted reliability with Cronbach's alpha ranging between 0.76 and 0.92 for the South African scale they had developed. Construct (factorial) validity was found for three dimensions of JRs (Growth and opportunities, Advancement and Organisational support).

Employee competence: The items were developed by expanding the competence-related conceptualisations of Grobbelaar et al.

TABLE 2: A summary of the measures and their use in the study.

\begin{tabular}{|c|c|c|c|c|c|}
\hline Measure & Authors & Variable category & Independent or dependent & Number items & Reliability (alpha) \\
\hline HRM Practices & Jacobs (2014) & Contextual & Independent & 17 & 0.945 \\
\hline Job demands: & $\begin{array}{l}\text { Bakker et al. (2003); Dwyer and Fox (2006); } \\
\text { Rothmann et al. (2006); Swart (2006) }\end{array}$ & Contextual & Independent & 12 & 0.827 \\
\hline JD1 - Workload / Work Pace & - & Contextual & Independent & - & $0.792 / 0.775$ \\
\hline JD2 - Organisation Systems Change & - & Contextual & Independent & - & 0.819 \\
\hline Job resources: & $\begin{array}{l}\text { Bakker et al. (2003); Dwyer and Fox (2006); } \\
\text { Rothmann et al. (2006); Swart (2006) }\end{array}$ & Contextual & Independent & 19 & 0.815 \\
\hline JR1 - Social support or Pay and benefit & & Contextual & Both & - & $0.765 / 0.905$ \\
\hline JR2 - Personal resources & - & Contextual & Both & - & 0.836 \\
\hline Employee competence & Jacobs (2014) & Proximate & Both & 8 & 0.912 \\
\hline P-E fit & Jacobs (2014) & Proximate & Independent & 5 & 0.819 \\
\hline Work engagement & Schaufeli et al. (2006) & Proximate & Both & 9 & 0.927 \\
\hline Well-being & Jacobs (2014) & Proximate & Both & 9 & 0.884 \\
\hline Burnout & Korunka et al. (2010) & Proximate & Both & 6 & 0.893 \\
\hline Turnover intention & Roodt (2004) & Distal & Dependent & 6 & 0.708 \\
\hline Employee performance & Jacobs (2014) & Distal & Dependent & 11 & 0.853 \\
\hline
\end{tabular}

$J D$, job demands; JR, job resources.

Note: The Cronbach's alpha reliabilities for two JDs and two JRs are presented in the shaded rows. Please see the full reference list of the article, Jacobs, C.T.G. \& Roodt, G. (2019). Predictive performance models in the South African Business Process Services industry. SA Journal of Industrial Psychology/SA Tydskrif vir Bedryfsielkunde, 45(0), a1493. https://doi.org/10.4102/sajip. v45i0.1493, for more information. 
(2004) on the employee, team and organisational levels. Eight items developed by Jacobs (2014) were used to measure the employee competence construct in this study, with the construct validity and reliability therefore previously unknown. An example item is: 'How adequately are employees equipped with appropriate skills to execute the core function of your organisation?', with the item(s) being scored on a seven-point intensity scale, with the extremes poles anchored (i.e. 1: Not adequate at all, indicating low intensity, and 7: More than adequately, indicating high intensity).

P-E fit: Billsberry et al. (2004) created five P-E fit dimensions: $\mathrm{P}-\mathrm{O}$ fit, $\mathrm{P}-\mathrm{V}$ fit, $\mathrm{P}-\mathrm{J}$ fit, $\mathrm{P}-\mathrm{G}$ fit and $\mathrm{P}-\mathrm{P}$ fit. As $\mathrm{P}-\mathrm{J}$ fit has been incorporated into Employee competence in this study, relevant items based on $\mathrm{P}-\mathrm{O}$ fit, $\mathrm{P}-\mathrm{V}$ fit, $\mathrm{P}-\mathrm{G}$ fit and $\mathrm{P}-\mathrm{P}$ fit were combined into one construct, for parsimonious purposes, in order to measure the broader $P-E$ fit construct. Five items developed by Jacobs (2014) were used to measure the P-E fit in this study, with the construct validity and reliability therefore previously unknown. An example is: 'How similar are your own values to those of your organisation?', with the item(s) being scored on a seven-point intensity scale with the extremes poles anchored (i.e. 1: Not similar at all indicating low intensity, and 7: Highly similar indicating high intensity).

Work engagement: Work engagement was defined by Schaufeli, Salanova, González-Romá, and Bakker (2002, p. 74) as '... a positive, fulfilling, work-related state of mind that is characterised by vigour, dedication, and absorption'. The three components of the Utrecht Work Engagement Scale (UWES) constitute proposed opposites of burnout (vigour vs. exhaustion; dedication vs. cynicism; absorption vs. ineffectiveness - also see Schaufeli, Bakker, \& Salanova, 2006). The shortened nine-item version of the UWES (Schaufeli \& Bakker, 2003, 2004) was used in this study. An example is: 'I am enthusiastic about my job'. The items are scored on sevenpoint intensity scales with the extremes poles anchored (i.e. 1: Never indicating low intensity, and 7: Always indicating high intensity). Schaufeli et al. (2006) reported reliability of the UWES-9 of a Cronbach's alpha higher than 0.80 across 10 European countries, including South Africa, with the internal consistencies above the value of 0.70 for the three engagement scales. Acceptable factorial validity of the UWES-9 was determined by Schaufeli et al. (2006) across 10 countries.

Well-being: Employee well-being incorporates both physical health (with the emphasis on overall physical welfare, rather than just the absence of disease or infirmity), as well as an integrated mental and/or social condition of wellness (World Health Organisation, 2006). The well-being scale therefore measures whether the employee is physically and mentally integrated enough to manage normal stresses in order to work in a productive manner. Nine items developed by Jacobs (2014) were used to measure well-being in this study, with the construct validity and reliability therefore previously unknown. An example reads: 'How good has your health been since you started working at the organisation?', with the items being scored on a seven-point intensity scale with the extremes poles anchored (i.e. 1: Not good indicating low intensity, and 7: Very good indicating high intensity).

Burnout: The Maslach Burnout Inventory - General Survey (MBI-GS) (Schaufeli, Leiter, Maslach, \& Jackson, 1996) includes three subscales, namely (1) Exhaustion, which refers to fatigue; (2) Cynicism, which refers to an indifference or a distant attitude towards one's work in general; and (3) Professional efficacy, which includes personal accomplishment, social and non-social accomplishments at work (Korunka, Tement, Zdrehus, \& Borza, 2010). Six items from the latter authors were used to measure the burnout construct. An example reads: 'I feel emotionally drained from my work' with the items being scored on a seven-point intensity scale with the extremes poles anchored (i.e. 1 Never, and 7: Every day). Storm and Rothmann (2003) reported reliabilities of Cronbach's alpha as follows in their validation study of the MBI-GS in the South African context: 0.88 for Exhaustion, 0.78 for Cynicism and 0.79 for Professional efficacy. The MBI-GS's validity was also confirmed as a three-factor model of burnout.

Turnover intention: The TIS- 6 was constructed as a 'conation (intention) to distinguish it from the affective (emotion) and the cognitive (knowledge) components of psychological activities' (Bothma \& Roodt, 2013, p. 2), with the supposition that intention of behaviour is a reliable determinant of the behaviour actually occurring. The TIS-6 of Roodt (2004) was used to measure turnover intention.

An example reads: 'How often have you considered leaving your job?', with the items scored by employing a seven-point intensity scale with the extremes poles anchored (i.e. 1: Never indicating low intensity, and 7: Always indicating high intensity). Reliability was confirmed by Bothma and Roodt (2013) in the South African context with a Cronbach's alpha of 0.80 . Criterion-predictive and differential validity of the instrument was confirmed by Bothma and Roodt (2013).

Employee performance: Employee performance centres on '... individual performance to established targets and performance standards' (South African Bureau of Standards, 2008 , p. 24). This measure includes first-call or first-contact resolution, turnaround, customer satisfaction, quality control and wasteful expenditure (including rework because of the fact that first-contact resolution could not be achieved). This measure was used as the dependent variable in the study. Employee performance was measured with 11 items as developed by Jacobs (2014), with the construct validity and reliability therefore previously unknown. An example is Item 100: 'How often do you manage to complete the number of required tasks per day?', with the items being scored on a seven-point intensity scale with the extremes poles anchored (i.e. 1: Never indicating low intensity, and 7: Always indicating high intensity).

Table 2 presents a summary of the measures, the number of items each and their use, as well as their reliabilities. The final 
instrument contained 106 items, with three to four items per construct, as recommended for theoretical and statistical analysis purposes (Hair, Black, Babin, \& Anderson, 2010).

\section{Research procedure}

A preliminary or pilot investigation was carried out to establish the face validity of the instrument in a two-pronged approach (Garson, 2012). Firstly, subject experts, the study supervisor and a statistical consultant assessed the instrument. Some changes to the items were suggested, which included that some questions were re-worded to improve understanding. Secondly, 15 respondents from a contact centre that facilitates mostly outbound calls participated in the pilot study by completing the survey (these were excluded from the final sample). They were requested to respond on items that were unclear.

Survey data were collected over a three-and-a-half-month period by providing paper surveys to 821 employees in 16 participating BPS organisations that met the sampling criteria and had volunteered to participate in the research.

\section{Statistical analyses}

The statistical analyses were conducted in a particular order. Descriptive statistical analyses were conducted first to scrutinise the measures' item distribution properties.

In the multivariate analysis stage of the data, exploratory factor analyses (EFAs) were first conducted to establish if original theoretical constructs could be replicated. This was necessitated because of the fact that the researcher had developed five of the ten scales and number of items, as well as because of the exploratory nature of the study. Secondly, item and iterative reliability analyses were then conducted on those established variables. Thirdly, all the variables were then subjected to a confirmatory factor analysis (CFA) to test the fit of the measurement models and the suitability of their use in the structural models. At this stage, some items were omitted to improve the model fit. Finally, structural equation models (SEMs) were then tested for structural model fit. Incremental and absolute fit statistics were used to report on model fit. IBM's SPSS (Version 22) was used to analyse the data with EQS (Version 6) for SEM, as EQS is robust in handling non-normal data (Bentler, 2006).

The summary results of the CFAs are presented and discussed per variable in terms of the absolute fit measures and incremental fit measures. Absolute fit measures are the chisquare $\left(\chi^{2}\right)$, degrees of freedom $(d f)$, the chi-square-degrees of freedom ratio $\left(\chi^{2} / d f\right)$ and the root mean square error of approximation (RMSEA). Incremental fit indices are the Bentler-Bonnett Normed Fit Index (NFI), Non-Normed Fit Index (NNFI) and the Comparative Fit Index (CFI) (Bentler, 2006; Hair et al., 2010). The required limits for fit indices are as follows:

- Maximum likelihood of model fit (relative chi-square measurement): $\chi^{2}$ /df related to better-fitting models on the order of 1:3 (or less), with the exception of excessively large samples and very complex models (Hair et al., 2010); some researchers allow $\chi^{2} / d f$ as high as 1:5 (Schumacker \& Lomax, 2004).

- NFI: 0.95 are good, between 0.90 and 0.95 adequate, and below 0.90 indicative of possible need to re-specify the model (Garson, 2015; Schumacker \& Lomax, 2004).

- NNFI: 0.95 and higher is indicative of a good fit for confirmatory purposes and a cut-off of 0.90 is adequate fit for exploratory purposes (Garson, 2015; Schumacker \& Lomax, 2004).

- CFI: 0.95 or higher is indicative of good fit for confirmatory purposes and 0.90 or higher is indicative of adequate fit for exploratory purposes (Garson, 2015).

- RMSEA: Good fit is indicated by RMSEA values of 0.05 or less (Schumacker \& Lomax, 2004), RMSEA of 0.05-0.08 is indicative of reasonable fit (Diamantopoulos \& Sigauw, 2000) and RMSEA of 0.10 or higher is indicative of poor fit (Garson, 2015).

This study was more exploratory in nature and an exploratory approach was thus followed in the multi-variate testing of goodness-of-fit (GOF) models, with the conclusions being closer to the exploratory side of the confirmatory-exploratory dimension (Boomsma, 2000). GOF was interpreted in light of the characteristics of the study with considerations to the complexity of the models; Hair et al. (2010) caution in adopting one-size-fits-all approach to GOF, specifically if the model is very complex.

\section{Ethical consideration}

All institutional research ethic protocols were observed and adhered to during the execution of this research project.

\section{Results}

Before proceeding with the CFAs, all measures were first subjected to EFAs (or dimensionality analysis) as briefly discussed below. The latter procedure involves conducting an item inter-correlation matrix on each measure. A KaiserMeyer-Olkin (KMO) measure of sampling adequacy (MSA), as well as a Bartlett's test of sphericity chi-square coefficient was calculated for each of these matrices to establish the factorability of the matrices. All these MSA values and chisquare coefficients were exceeding the specified criteria and suggested that all the matrices could be factor analysed. The number of eigenvalues larger than unity, as well as scree plots was used to determine how many factors should be extracted. In the case of both JDs and JRs, two factors were extracted. CFAs were subsequently conducted on these extracted factors to test their measurement model fit.

\section{Dimensionality analysis}

The measurement scales that yielded a single factor, as indicated by eigenvalues larger than unity and reiterated by the scree plot, included the HRM Practices Scale, the Maslach Burnout Index (General Survey) Scale, the Employee 
Competence Scale, the P-E Fit Scale, the Utrecht Work Engagement Scale and the Turnover Intention Scale. The HRM Practices Scale obtained a KMO sampling adequacy value of 0.951 , with a significant Bartlett's test of sphericity chi-square value $\left(\chi^{2}=4928.806 ; p=0.001\right)$. The Employee Competence Scale obtained a KMO sampling adequacy value of 0.876 , with a significant Bartlett's test of sphericity chi-square value $\left(\chi^{2}=2474.291 ; p=0.001\right)$. The EFA for the P-E Fit Scale obtained a KMO sampling adequacy value of 0.714, with a significant Bartlett's test of sphericity chi-square value $\left(\chi^{2}=1080.441 ; p=0.001\right)$. The Utrecht Work Engagement Scale obtained a KMO sampling adequacy value of 0.914, with a significant Bartlett's test of sphericity chi-square value $\left(\chi^{2}=3098.452 ; p=0.001\right)$. The Maslach Burnout Index (General Survey) Scale, obtained a KMO sampling adequacy value of 0.844, with a significant Bartlett's test of sphericity chi-square value $\left(\chi^{2}=1683.172 ; p=0.001\right)$. The Turnover Intention Scale obtained a KMO sampling adequacy value of 0.736 , with a significant Bartlett's test of sphericity chi-square value $\left(\chi^{2}=\right.$ 581.867; $p=0.001)$. It was noted that Item G82 did not fit well and was removed from the scale. The KMO value was deemed to be acceptable for all of the aforementioned scales (Hair et al., 2010), with the item inter-correlation matrix being factor analysable and Bartlett's test of sphericity allowing for the identity matrix null hypothesis not to be supported.

The Job Demands Scale, the Job Resources Scale, the Employee Well-being Scale and the Employee Performance Scale constituted two factors each. The Job Demands Scale obtained a KMO sampling adequacy value of 0.550 , with a significant Bartlett's test of sphericity chi-square value $\left(\chi^{2}=\right.$ 203.816; $p=0.001)$. The Job Resources Scale obtained a KMO sampling adequacy value of 0.516 , with a significant Bartlett's test of sphericity chi-square value $\left(\chi^{2}=68.906 ; p=0.001\right)$. The Well-being Scale obtained a KMO sampling adequacy value of 0.888 , with a significant Bartlett's test of sphericity chisquare value $\left(\chi^{2}=1991.028 ; p=0.001\right)$. The Employee Performance Scale obtained a KMO sampling adequacy value of 0.872 , with a significant Bartlett's test of sphericity chi-square value $\left(\chi^{2}=1826.700 ; p=0.001\right)$. It was noted that Item 198 did not fit well and was removed from the scale. The $\mathrm{KMO}$ value was deemed to be great for each of the beforementioned scales (Hair et al., 2010), with the item inter- correlation matrix being factor analysable. Bartlett's test of sphericity allowed the rejection of the identity matrix null hypothesis. Two factors were extracted for each of the beforementioned scales.

\section{Testing the measurement models for model fit}

Mardia's (1970) normalised coefficient of multivariate kurtosis was considered in all of the measurement models, and the adjusted or 'robust' Yuan-Bentler fit statistics were then utilised if applicable. The summary of the absolute and incremental fit statistics for all the different measurement models is reported in Table 3.

It is evident from Table 3 that most of the measures have a good or acceptable measurement model fit, except for P-E fit which will not be interpreted further. It is further noted that the incremental fit indices for Employee Competence, Work Engagement, Well-being and Burnout were slightly below the recommended cut-off value of 0.90 (and in some cases, the chi-square-degrees of freedom ratio was above the recommended cut-off value of 1:5 as per Schumacker \& Lomax, 2004). Given the exploratory nature of the study (Boomsma, 2000), these remaining measurement models are suitable for inclusion in the structural models to be tested further in the study and will be cautiously interpreted for exploratory purposes (Hair et al., 2010).

\section{Testing the structural models for model fit}

Two structural models (refer to specified Models 1 and 2 in Figures 1 and 2) were tested in this study.

The specified Model 1 had to be modified by following a systematic process to remove items because of low $R^{2}$-values, in order to obtain good model fit statistics as displayed in Table 4 . The finally tested and modified model to predict Turnover intention appears in Figure 3.

It is evident from Figure 3 that the two proximate outcomes Well-being and Engagement were omitted from the model to obtain a more parsimonious model and a better model fit. Social support was also removed from JR1 owing to low item $R^{2}$-values with Engagement and Burnout. Perceived HRM

TABLE 3: Confirmatory factor analysis (goodness-of-fit statistics for the measurement models of the different variables, $n=487$ ).

\begin{tabular}{|c|c|c|c|c|c|c|c|c|c|}
\hline Number models & $\begin{array}{c}\text { Multivariate } \\
\text { Kurtosis }\end{array}$ & $\chi^{2}$ & $d f$ & $\chi^{2} / d f$ & NFI & NNFI & CFI & RMSEA & $\overline{\text { Confidence interval }}$ \\
\hline 3. HRM practices & 45.970 & 581.767 & 119 & 4.889 & 0.903 & 0.909 & 0.921 & 0.089 & $0.082-0.097$ \\
\hline 1. Job demands & 30.849 & 136.950 & 50 & 2.739 & 0.920 & 0.930 & 0.947 & 0.060 & $0.048-0.072$ \\
\hline 1. Employee Competence & 51.024 & 178.628 & 20 & 8.931 & 0.890 & 0.860 & 0.900 & 0.128 & $0.111-0.146$ \\
\hline 2. P-E fit & 26.837 & 131.862 & 2 & 65.93 & 0.766 & 0.301 & 0.767 & 0.367 & $0.314-0.420$ \\
\hline 1. Work engagement & 49.169 & 254.584 & 27 & 9.429 & 0.889 & 0.865 & 0.899 & 0.132 & $0.117-0.147$ \\
\hline 1. Burnout & 31.042 & 98.588 & 9 & 10.95 & 0.933 & 0.897 & 0.938 & 0.144 & $0.118-0.169$ \\
\hline 2. Turnover intention & 2.034 & 5.183 & 2 & 2.592 & 0.988 & 0.978 & 0.993 & 0.057 & $0.000-0.120$ \\
\hline 3. Employee perform & 37.952 & 62.212 & 14 & 4.444 & 0.930 & 0.916 & 0.944 & 0.085 & $0.064-0.106$ \\
\hline
\end{tabular}

$\mathrm{NFI}$, Normed Fit Index; NNFI, Non-Normed Fit Index; CFI, Comparative Fit Index; RMSEA, root mean square error of approximation; $d f$, degrees of freedom; $\chi^{2}=$ chi-square; $\chi^{2} / d f$, chi-square-degrees of freedom ratio.

Note: Mardia's coefficient of multivariate kurtosis is reported. All indices are at $p \leq 0.001$, unless indicated otherwise. 
TABLE 4: Goodness-of-fit (Yuan-Bentler correction) indices for Structural Model 1 predicting turnover intention $(n=509)$.

\begin{tabular}{lcccccccc}
\hline Number model & $\begin{array}{c}\text { Multivariate } \\
\text { Kurtosis }\end{array}$ & $\chi^{2}$ & $d f$ & $\chi^{2} / d f$ & NFI & NNFI & CFI & RMSEA \\
interval
\end{tabular}

$\mathrm{NFI}$, Normed Fit Index; NNFI, Non-Normed Fit Index; CFI, Comparative Fit Index; RMSEA, root mean square error of approximation; $d f$, degrees of freedom; $\chi^{2}$, Satorra-Bentler Scaled chi-square; $\chi^{2} / d f$, chi-square-degrees of freedom ratio.

Note: Mardia's coefficient of multivariate kurtosis is reported. All indices are at $p \leq 0.001$, unless indicated otherwise.

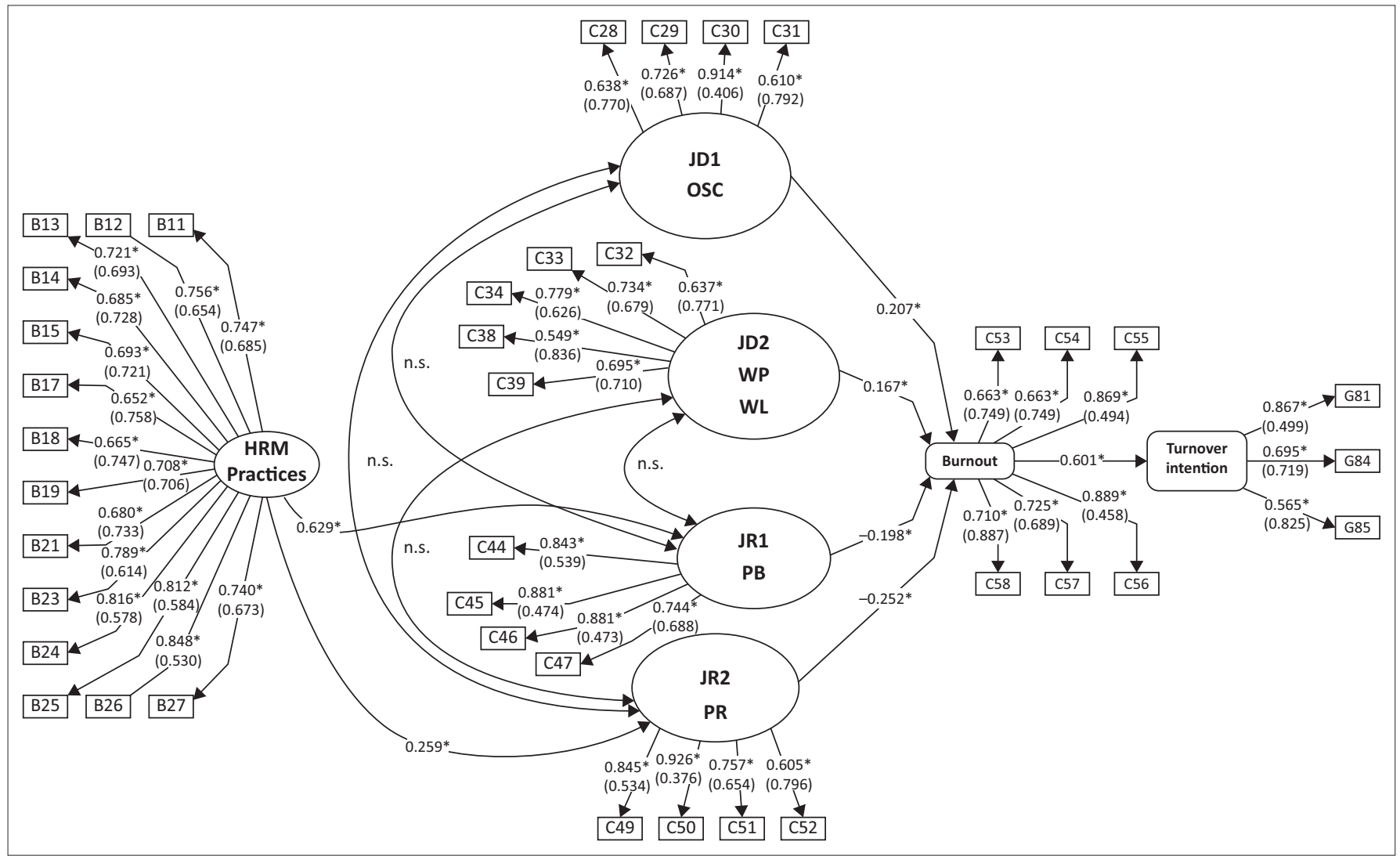

JD, job demands; OSC, organisational systems change; WP, work pace; WL, workload; JR, job resources; SS, social support; PB, pay and benefits; PR, personal resources; n.s., not significant. Note: Standardised path coefficients detailed with unstandardised path coefficients in parentheses. $*, p<0.05$.

FIGURE 3: Tested and modified Model 1 - Prediction of Turnover Intention.

practices are significantly related to JR1 (Pay and benefits with a standardised path coefficient of $\beta=0.629$ ) and JR2 (Personal resources with $\beta=0.259)$, but not to JD1 (Organisational systems change) and JD2 (Work pace and Workload). All JDs (JD1 with $\beta$ $=0.207$; JD2 with $\beta=0.167$ ) were positively related to Burnout, which in turn is significantly related to Turnover intention (with $\beta=0.601$ ). All JRs (JR1 with $\beta=-0.198$; JR2 with $\beta=$ -0.252 ) were negatively related to Burnout. The relationships between JDs and JRs were statistically insignificant. The absolute fit indices as displayed in Table 4 are good - the incremental fit indices NFI, NNFI and CFI, however, were below the recommended value 0.90 . The incremental fit indices that approached 0.90 are indicative of the fact that the model can cautiously be utilised for exploratory purposes and should be interpreted with care (Hair et al., 2010). Again, it is noted that the study is more exploratory in nature and an exploratory approach was thus followed in the multivariate testing of GOF model (Boomsma, 2000).

The overall variance of Turnover intention explained by Model 1 is $R^{2}=0.361$. RO1 of the study is hereby achieved and both
$\mathrm{H} 1$ and $\mathrm{H} 3$ are supported by the research data with the exclusion of the Well-being and Engagement variables in the model which is attributed to the large degree of overlap between these three variables.

The specified Model 2 had to be modified to obtain good model fit statistics as displayed in Table 5. The finally tested and modified model to predict Individual performance appears in Figure 4.

It is evident from Figure 4 that Social support was removed from JR1 owing to low $R^{2}$-values with Engagement items. Perceived HRM practices are significantly related to JR1 (Pay and benefits with $\beta=0.625$ ) and JR2 (Personal resources with $\beta=$ 0.239), but not to JD1 (Organisational systems change) and JD2 (Work pace and Workload). HRM practices are also directly linked to Engagement $(\mathrm{b}=0.338)$ and to Employee competence $(\mathrm{b}=0.549)$. JRs (JR1 - Pay and benefits with $\beta=0.060$, and JR2 - Personal resources with $\beta=0.275$ ) are positively related to Engagement and JDs (JD1 - Organisational systems change with $\beta=-0.114$, and JD2 - Work pace and Workload with $\beta=-0.016$ ) 
TABLE 5: Goodness-of-Fit (Yuan-Bentler correction) indices for Structural Model 2 predicting individual performance $(n=509)$.

\begin{tabular}{|c|c|c|c|c|c|c|c|c|c|}
\hline Number models & $\begin{array}{l}\text { Multivariate } \\
\text { Kurtosis }\end{array}$ & $\chi^{2}$ & $d f$ & $\chi^{2} / d f$ & NFI & NNFI & CFI & RMSEA & $\begin{array}{c}\text { Confidence } \\
\text { interval }\end{array}$ \\
\hline $\begin{array}{l}\text { 3rd iteration of } \\
\text { Model } 2\end{array}$ & 534.97 & 2268.47 & 1107 & 2.05 & 0.834 & 0.901 & 0.907 & 0.045 & $0.043-0.048$ \\
\hline
\end{tabular}

NFI, Normed Fit Index; NNFI, Non-Normed Fit Index; CFI, Comparative Fit Index; RMSEA, root mean square error of approximation; $d f$, degrees of freedom; $\chi^{2}$, Yuan-Bentler scaled chi-square; $\chi^{2} / d f$, chi-square-degrees of freedom ratio.

Note: Mardia's coefficient of multivariate Kurtosis is reported; Yuan, Lambert and Fouladi's coefficient of multivariate kurtosis is reported. All indices are at $p \leq 0.001$, unless indicated otherwise.

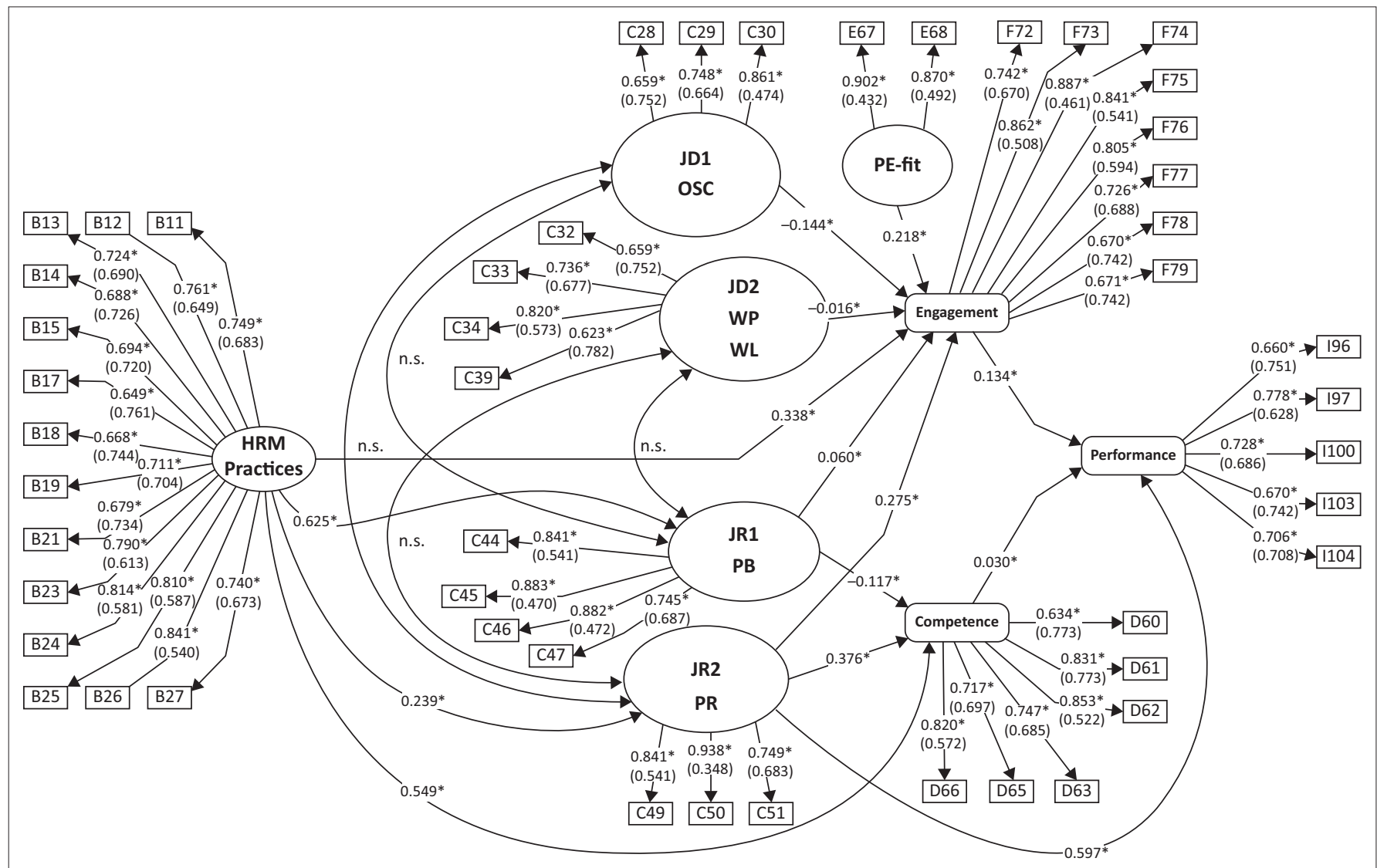

JD, job demands; OSC, organisational systems change; WP, work pace; WL, workload; JR, job resources; SS, social support; PB, pay and benefits; PR, personal resources; n.s., not significant. Note: Standardised path coefficients detailed with unstandardised path coefficients in parentheses.

$*, p<0.05$.

FIGURE 4: Tested and modified Model 2 - Prediction of Individual Performance.

are negatively related to Engagement. JRs (JR1 - Pay and benefits with $\beta=-0.117$, and JR2 - Personal resources with $\beta=0.376$ ) are respectively negatively and positively related to Employee competence, while JDs (JD1 - Organisational systems change, and JD2 - Work pace and Workload) are unrelated to Employee competence. JR2 (Personal resources) is also directly related $(\beta=$ $0.597)$ to Individual performance, while Engagement $(\beta=0.134)$ and Employee competence $(\beta=0.030$ ) are also (but more weakly) related to Individual performance. Despite the low measurement fit indices for $P-E$ fit, two items were retained that were significantly related to Engagement. The fit indices as displayed in Table 5 are good despite the NFI being slightly below 0.90 . The overall variance of Individual performance explained by Model 2 is $R^{2}=0.458$. RO2 is hereby achieved and both $\mathrm{H} 2$ and $\mathrm{H} 4$ are supported by the research data.

\section{Discussion}

The research problem investigated in this study can be traced back to a systematic literature review study conducted earlier by Jacobs and Roodt (2011). The latter study identified a number of variables that were empirically linked to individual performance (on a bivariate level) in the BPS environment. However, not any study could be found that operationalised and tested multivariate individual performance models in the BPS industry; consequently, the main research question of this study was phrased as: 'How can the human capital predictive model of employee performance in the BPS industry, be operationalised and empirically tested?' As stated earlier, two research objectives (ROs) were formulated, namely:

RO1: To establish if HRM practices, JRs and JDs, in combination with proximate variables (well-being, burnout and engagement) predict the distal outcome, turnover intention.

RO2: To establish if HRM practices, JRs and JDs, in combination with proximate variables (P-E fit, employee competence and engagement) predict the distal outcome, individual performance.

The main contribution of the study lies therein that it operationalised and tested a multivariate model of employee performance in the South African BPS industry. 


\section{Summary of the research results}

The results of the study should be interpreted within the framework of the systems theory (Dostal et al., 2005; Jaaron \& Backhouse, 2010) and force field analysis (Lewin, 1951). The two models that were tested in the study contain variables that are systemically linked and that may function as a system within a larger system. It is, for instance, argued that HRM practices in combination with particular JRs and JDs function as a contextual system that results in particular proximate outcomes. In turn, these said variables combine into a larger system, which may result in distal outcomes. The research results will be discussed in terms of the two stated research objectives.

\section{Research results in respect of RO1}

Model 1, developed for the prediction of turnover intention, was confirmed in this study. It was established that HRM practices are related to JR1 (pay and benefits) and to JR2 (personal resources), but not to JDs (JD1 - organisational systems change; JD2 - work pace and workload). All JRs and JDs in the model were related to burnout, which in turn is related to turnover intention. Well-being and engagement were omitted to create a more parsimonious model and a better model fit. These findings suggest that HRM practices provide the platform for developing JRs that will reduce the occurrence of burnout and promote the intention to stay. These results are in support of $\mathrm{H1}$ (H1 - Perceived HRM practices, JDs and JRs are individually or interactively predictors of proximate outcomes - well-being, burnout and engagement) and H3 (H3 Perceived contextual factors, as well as proximate outcomes of wellbeing, burnout and engagement, are related to turnover intention).

Liu et al.'s (2007) model provides a well-substantiated taxonomy of HRM practices in the context of employee retention in the BPS organisation. Career promotion and succession are limited in the BPS industry (Batt, 2002; Gorjup et al., 2008), but internal advancement has a direct influence on commitment levels (or the intention to stay). Participation programmes, flexitime and grievance procedures positively impact retention (Batt, 2002; Cox et al., 2000). Long-term employment reassurance (job security) is essential for commitment (or the intention to stay) (Batt, 2002; Zapf et al., 2003). The research results of this study confirm the said relationships between the contextual factors and burnout, as well as individual's intention to stay (a.k.a. employee retention).

JDs (as identified by Bakker et al., 2003; Dwyer \& Fox, 2006) include changes in tasks, work pace demands and workload that may have negative effects (burnout) if persisting over a long period. JRs (as identified by Bakker et al., 2003; Dwyer \& Fox, 2006) include job characteristics, social support, time control, individual performance feedback and personal resources. It is clear that most of these mentioned JDs and JRs are, respectively, positively and negatively related to burnout in this study, which is again linked to the intention to leave or to stay.

\section{Research results in respect of RO2}

Model 2, developed for the prediction of individual performance, was confirmed in this study. It was established that HRM practices are directly and relatively strongly related to employee engagement and to employee competence, but also more weakly related to JR1 (pay and benefits) and to JR2 (personal resources), but not to JDs (JD1 - organisational systems change; JD2 - work pace and workload). Both JDs (JD1 - organisation systems change as well as JD2 - work pace and workload) and P-E fit are related to engagement, but not to employee competence. Owing to the poor measurement fit indices of P-E fit, no further discussion on this aspect will be included here. JRs (JR1 - pay and benefits; JR2 - personal resources) are related to engagement and to employee competence, while JR2 is also directly related to individual performance. JDs and JRs are unrelated. The relationship between engagement and employee competence with individual performance is rather weak, compared to the relationship between personal resources and individual performance. These results are in support of H2 (H2 - Perceived HRM practices, JDs and JRs are individually or interactively predictors of proximate outcomes employee competence and work engagement) and of H4 (H4Perceived contextual factors, as well as proximate outcomes P-E fit, employee competence and work engagement, are related to individual performance).

Liu et al.'s (2007) model also provides a sound taxonomy of HRM practices in the context of individual performance in the BPS organisation. Several authors (Frenkel, Tam, Korczynski, \& Shire, 1998; Houlihan, 2000; Townsend, 2007) are of the opinion that most of the skills development efforts should focus on technical competence and product knowledge, in order to meet individual performance pressures. Pay-for-performance is a common practice in sales-orientated BPS environments (Batt et al., 2009) in order to promote motivation (or commitment) levels. Promoting job security (or long-term employment reassurance) is essential for achieving these said commitment levels (Batt, 2002; Zapf et al., 2003). This study's results confirm these links between HRM practices and the proximate outcome (engagement), as well as the distal outcome (individual performance).

This study also confirms the general research trend that JDs and JRs are related to work engagement (Demerouti \& Bakker, 2011; Demerouti et al., 2001; Schaufeli \& Taris, 2014). Only JRs (but not JDs) are related to employee competence in this study. However, HRM practices are more strongly related to work engagement and employee competence compared to JDs and JRs. This surprising finding may be attributed to the fact that HRM practices as a contextual variable contributes more directly to establishing engagement and employee competence when compared to JRs and/or JDs. Work engagement is more strongly related to individual performance, compared to employee competence, but both are weaker linked to individual performance when compared to personal resources, which has the strongest link. 
This surprising finding can be attributed to the fact that personal resources are more directly linked to individual performance compared to employee competence and work engagement, which are influenced by a range of other variables.

\section{Conclusion}

To the knowledge of the authors, this is the first SA study in the BPS industry that operationalised and tested multivariate models for the prediction of employee retention, as well as individual performance. Good fit statistics were obtained for testing both the measurement models (with the exception of P-E fit) and the structural models.

Both the stated ROs of the study were achieved. More specifically, the following conclusions can be drawn from the findings in respect of $\mathrm{RO} 1$ :

HRM practices are related to JRs (both JR1 and JR2), but not to JDs, and all JRs and JDs (although unrelated) predict the proximate outcome burnout, which is in turn related to the distal outcome, turnover intention. RO1 is hereby achieved and both $\mathrm{H} 1$ and $\mathrm{H} 3$ are supported. Well-being and engagement were omitted from the model to improve model fit and to provide a more parsimonious model.

In respect of $\mathrm{RO} 2$, the study established that HRM practices in combination with JRs predict proximate outcomes, employee competence and work engagement (P-E fit is only related to engagement), but HRM practices have a stronger direct link with engagement and employee competence, compared to JRs and JDs (in the case of engagement) and only JRs (in the case of competence). Engagement and employee competence are in turn related to the distal outcome individual performance, but personal resources are more strongly associated with individual performance, compared to the two first mentioned variables. $\mathrm{RO} 2$ is hereby achieved and both $\mathrm{H} 2$ and $\mathrm{H} 4$ are supported.

\section{Implications}

The study has important implications for executives, managers and HR practitioners in the BPS industry, as well as for researchers: It can be noted that HRM practices combined with JRs relative to JDs result in reducing burnout in the short term. HRM practices therefore contribute to the development and strengthening of JRs. The occurrence of burnout is in this case related to turnover intention. It seems that more effective HRM practices and/or JRs reduce the occurrence of burnout and ultimately turnover intention.

Executives and managers in the BPS industry can take note of the fact that HRM practices on their own or combined with JRs may create a context that is conducive for the promotion of employee competence and work engagement in the short term, but also employee performance in the longer term. But this will only happen if the HRM practices are perceived as positive and effective. It seems that managers and HR practitioners in the sampled organisations were successful in creating such effective HRM practices and such a conducive HRM context.

The results suggest that HR practitioners and managers in the BPS industry in this study successfully developed HRM practices that are positively perceived with JRs counteracting the impact of JDs; they have succeeded in creating a context that is conducive for the development of employee competence and work engagement in the short term with a clear impact on employee performance in the long term.

\section{Limitations of the study and suggestions for future research}

The study only used a cross-sectional sample to collect that data for this exploratory study. Individuals were used as the unit of analysis in this study. As a consequence, there may be artificially enhanced levels of common method variance where individuals have completed measures for both the independent and for the dependent variables. A multi-level study design, a longitudinal design, or even a design where an objective individual performance measure is used, may therefore yield different results and should therefore be explored in future studies.

It is proposed that future research (if research ethics principles permit) should make use of multi-level studies where data are captured on different levels. Alternatively, data for the dependent variable can be captured on an objective level. A longitudinal research design may shed light on the cause and effect relationships in different time periods between variables in the model which could not be established by this cross-sectional study.

To conclude, the study set out to develop and test multivariate models of employee turnover intention and individual performance in the SA BPS industry. Two ROs and four hypotheses were formulated in the study. In order to operationalise the ROs and test the hypotheses, a crosssectional research design was used to collect data and multivariate data analyses were conducted to establish $e x$ post facto relationships between model variables. The first model that predicted turnover intention, as well as the second model that predicted individual performance was confirmed and support for all four hypotheses was established. Both the ROs of the study were hereby achieved.

\section{Acknowledgements Competing interests}

The authors declare that they have no financial or personal relationships which may have inappropriately influenced them in writing this article.

\section{Authors' contribution}

C.T.G.J. conducted the research for his PhD study. This article is based on a portion of his doctoral thesis. G.R. who was his supervisor for his doctoral study wrote the article. 


\section{References}

Aksin, Z., Armony, M., \& Mehrotra, V. (2007). The modern call center: A multidisciplinary perspective on operations management research. Production and Operations
Management, 16, 665-688. https://doi.org/10.1111/j.1937-5956.2007.tb00288.x

Arthur, W. Jr., Bell, S. T., Doverspike, D., \& Villado, A. J. (2006). The use of personorganization fit in employment decision making: An assessment of its criterion
related validity. Journal of Applied Psychology, 91, 786-801. https://doi. related validity. Journal of Applie
org/10.1037/0021-9010.91.4.786

Axtell, C. M., Parker, S. K., Holman, D., \& Totterdell, P. (2007). Enhancing customer service: Perspective taking in a call centre. European Journal of Work and Organizational Psychology, 16, 141-168. https://doi.org/10.1080/13594320 600989583

Bagnara, S., \& Marti, P. (2001). Human work in call centres: A challenge for cognitive ergonomics. Theoretical Issues in Ergonomics Science, 2, 223-237. https://doi. org/10.1080/14639220110104943

Bakker, A. B., \& Demerouti, E. (2016). Job Demands-Resources theory: Taking stock and looking forward. Journal of Occupational Health Psychology. Advance online publication. https://doi.org/10.1037/ocp0000056

Bakker, A. B., Demerouti, E., \& Schaufeli, W. B. (2003). Dual processes at work in a call centre: An application of the Job Demands-Resources model. European Journal of Work and Organizational Psychology, 12, 393-417. https://doi.org/10.1080/ 13594320344000165

Banks, D., \& Roodt, G. (2011). The efficiency and quality dilemma: What drives South African call centre management performance indicators? SA Journal of Huma Resource Management, 9, 1-17. https://doi.org/10.4102/sajhrm. v9i1.331

Batt, R. (2002). Managing customer services: Human resource practices, quit rates, and sales growth. Academy of Management Journal, 45, 587-597. https://doi. org $/ 10.2307 / 3069383$

Batt, R., Holman, D., \& Holtgrewe, U. (2009). The globalization of service work: Comparative institutional perspectives on call centers. Industrial and Labor Relations Review, 62, 452-488. https://doi.org/10.1177/001979390906200401

Belt, V., Richardson, R., \& Webster, J. (2002). Women, social skill and interactive service work in telephone call centres. New Technology, Work and Employment, 17, 20-34. https://doi.org/10.1111/1468-005X.00091

Bentler, P. M. (2006). EQS 6 Structural Equations Program Manual. Encino, CA: Multivariate Software, Inc.

Billsberry, J., Marsh, P., \& Moss-Jones, J. (2004). Mapping organizational members' sense of fit. Conference proceedings of the Academy of Management Annual sense of fit. Conference proceedings of the Acade
Meeting, August 2004, New Orleans, LA, (pp. 1-26).

Boomsma, A. (2000). Reporting analyses of covariance structures. Structural Equation Modeling, 7, 461-483. https://doi.org/10.1207/S15328007SEM0703_6

Bothma, F. C., \& Roodt, G. (2013). The validation of the turnover intention scale. SA Journal of Human Resource Management, 11, 1-12. https://doi.org/10.4102/ sajhrm.v11i1.507

Burgers, A., De Ruyter, K., Keen, C., \& Streukens, S. (2000). Customer expectation dimensions of voice-to-voice service encounters: A scale-development study. International Journal of Service Industry Management, 11, 142-161. https://doi. org/10.1108/09564230010323642

Callaghan, G., \& Thompson, P. (2002). 'We recruit attitude': The selection and shapin of routine call centre labour. Journal of Management Studies, 39, 233-254. of routine call centre labour. Journal of
https://doi.org/10.1111/1467-6486.00290

Campbell, C. (2003). Burnout in a customer service environment. Unpublished Master's thesis, Potchefstroom, South Africa: University of the North-West.

Carrim, N., Basson, J., \& Coetzee, M. (2006). The relationship between job satisfaction and locus of control in a South African call centre environment. South African Journal of Labour Relations, 30, 66-81.

Cox, C., Griffiths, A., \& Rial-González, A. (2000). Research on work-related stress. Luxembourg: Office for Official Publications of the European Communities

Demerouti, E., \& Bakker, A. B. (2011). The Job Demands-Resources model: Challenges for future research. SA Journal of Industrial Psychology, 37, 1-9. https://doi. org/10.4102/ sajip.v37i2.974

Demerouti, E., Bakker, A. B., Nachreiner, F., \& Schaufeli, W. B. (2001). The job demandsresources model of burnout. Journal of Applied Psychology, 86, 499-512. https:// doi.org/10.1037//D021-9010.86.3.433

Diamantopoulos, A., \& Siguaw, J. A. (2000). Introducing LISREL. London: Sage.

Dimension Data. (2008). Global Contact Centre Benchmarking Report 2008: A decade of insight. Johannesburg: Dimension Data.

Dimension Data. (2014). Dimension Data's 2013/14 global contact centre benchmarking summary report. Retrieved from http://www.dimensiondata.com/ Global/Downloadable\%20Documents/2013_14_benchmarking\%20summary\% 20report.pdf

Dladla, T. (2009). The effects of locus of control on the relationship between organisational climate and job satisfaction, life satisfaction and self-esteem in a call centre. Unpublished Master's thesis, Johannesburg, South Africa: University of Witwatersrand.

Dostal, E., Cloete, A., \& Jaros, G. (2005). Biomatrix: A systems approach to organisational and societal change. Cape Town: Mega Digital.

Du Preez, J. J. (2008). Call Centre design, operation and optimisation - A structured and scientific based approach. Unpublished Master's thesis, Stellenbosch, South Africa: University of Stellenbosch.

Dwyer, D. J., \& Fox, M. L. (2006). The relationship between job demands and key performance indicators: Moderating effects of job resources in call centers. Journal of Business and Management, 12, 127-145.
Engman, M. (2007). Expanding international supply chains: The role of emerging economies in providing IT and business process services. Organisation for Economic Co-operation and Development Trade Policy Working Paper No. 52, Economic Co-
Paris, France.

Fitz-Enz, J. (2009). The ROI of human capital (2nd edn.). Amacom: New York.

Frenkel, S., Tam, M., Korczynski, M., \& Shire, K. (1998). Beyond bureaucracy? Work organization in call centres. The International Journal of Human Resource Management, 9, 957-979. https://doi.org/10.1080/095851998340694

Frost \& Sullivan Consulting (2009). Gauteng BPO Marketing Strategy. An analysis of market and industry conditions for the development of an effective marketing strategy. Cape Town: Frost \& Sullivan.

Garson, G. D. (2012). Structural equation modelling. Blue Book Series. Asheboro, NC: Statistical Associates Publishing.

Garson, G. D. (2015). Structural equation modeling. Blue Book Series. Asheboro, NC: Statistical Associates Publishing.

Gorjup, M. T., Valverde, M., \& Ryan, G. (2008). Promotion in call centres: Opportunities and determinants. Journal of European Industrial \& Training, 32, 45-62. https:// doi.org/10.1108/03090590810846566

Grobbelaar, R. L., Roodt, G., \& Venter, A. (2004). Critical competencies to promote a customer service core capability in a human resources call centre. SA Journal of Human Resource Management, 2, 16-24. https://doi.org/10.4102/sajhrm.v2i3.45

Hair, J. F., Black, W. C., Babin, J. B., \& Anderson, R. E. (2010). Multivariate data analysis (7th edn.). Upper Saddle River, NJ: Prentice Hall.

Higgs, M. (2004). A study of the relationship between emotional intelligence and performance in UK call centres. Journal of Managerial Psychology, 19, 442-454. performance in UK call centres. Journal of Manat
https://doi.org/10.1108/02683940410537972

Houlihan, M. (2000). Eyes wide shut? Querying the depth of call centre learning. Journal of European Industrial Training, 24, 228-240. https://doi.org/10.1108/ 03090590010321197

Jaaron, A. A., \& Backhouse, C. J. (2010). Systems thinking for call centre service operations: Implications for affective commitment in manufacturing enterprises.
The Services Industries Journal, 31, 613-628. https://doi.org/10.1080/02642069

Jacobs, C. (2014). A human capital predictive model for employee performance. Unpublished PhD thesis, Johannesburg, South Africa: University of Johannesburg.

Jacobs, C., \& Roodt, G. (2011). A human capital predictive model for agent performance in contact centres. SA Journal of Industrial Psychology, 37, 1-19. https://doi. org/10.4102/sajip.v37i1.940

Jones, R. (2008). South African national BPO \& call centre report. Johannesburg: C3 Africa and the Multimedia Group.

Kerstin, N. (2005). Call centre work: Characteristics, physical, and psychosocial exposure, and health related outcomes. Unpublished doctoral dissertation, Linköping University. Linköping, Sweden.

Korunka, C., \& Tement, S., Zdrehus, C., \& Borza, A. (2010). Burnout: Definition, recognition and prevention approaches. Retrieved from https://tinyurl.com/ o3kcqvg

Koyana, B. (2010). SA's BPO sector under threat. Retrieved from https://www.itweb. co.za/index. php?option=com_content \&view=article\&id=38090:sas-bpo-sector under-threat $\&$ catid $=118 \&$ Itemid $=66$

Le Fevre, M. (2003). Somatic and cognitive stress management techniques: Their effect on measures of stress and competency in managers. Unpublished doctoral dissertation, Auckland University of Technology. Auckland, New Zealand.

Lewin, K. (1951). Field Theory in Social Science. New York: Harper \& Row.

Liu, Y., Combs, J. G., Ketchen Jr., D. J., \& Ireland, R. D. (2007). The value of human resource management for organisational performance. Business Horizons, 50, 503-511. https://doi.org/10.1016/j.bushor.2007.07.002

Lu, C., Wang, H., Lu, J., Du, D., \& Bakker, A. B. (2014). Does work engagement increase person-job fit? The role of job crafting and job insecurity. Journal of Vocational Behavior, 84, 142-152. https://doi.org/10.1016/j.jvb.2013.12.004

Mahesh, V. S., \& Kasturi, A. (2006). Improving call centre agent performance: A UKIndia study based on the agents' point of view. International Journal of Service IndustryManagement,17,136-157.https://doi.org/10.1108/09564230610656971

Malhotra, N., Budhwar, P., \& Prowse, P. (2007). Linking rewards to commitment: An empirical investigation of four UK call centres. International Journal of Human Resource Management, 18, 2095-2127. https://doi.org/10.1080/0958519070 1695267

Mardia, K. V. (1970). Measures of multivariate skewness and kurtosis with applications. Biometrika, 57, 519-530. https://doi.org/10.1093/biomet/57.3.519

McCulloch, M. C., \& Turban, D. B. (2007). Using person-organization fit to select employees for high-turnover jobs. International Journal of Selection and Assessment, 15, 63-71. https://doi.org/10.1111/j.1468-2389.2007.00368.x

Moller, Y., Crous, F., \& Schepers, J. M. (2004). ' $n$ Ondersoek na die persoonlikheidseienskappe van inbelsentrumkonsultante [An investigation into personality traits of call centre consultants]. SA Journal of Industrial Psychology, 30, 74-84. https://doi.org/10.4102/sajip.v30i2.146

Nel, H., \& De Villiers, W. S. (2004). The relationship between emotional intelligence and job performance in a call centre environment. SA Journal of Industrial Psychology, 30, 75-81. https://doi.org/10.4102/sajip.v30i3.159

Nicholls, M. L. (2006). The validation of a test battery for the selection of call centre operators in a communications company. Unpublished Master's thesis, Pretoria, South Africa: University of South Africa.

Ojha, A. K., \& Kasturi, A. (2005). Successful call centre employees: Understanding employee attributes and performance evaluation processes. IIMB Management Review, 17, 93-102. 
Robbins, S. P., Judge, T. A., Odendaal, A., \& Roodt, G. (2009). Organisational behaviour: Global and South African perspectives. Cape Town, South Africa: Pearson Education.

Robinson, I. (2006). Human resource management in organisations. London: Chartered Institute of Personnel and Development.

Roodt, G. (2004). The turnover intention scale. Unpublished document. Johannesburg University of Johannesburg.

Rose, E., \& Wright, G. (2005). Satisfaction and dimensions of control among call centre customer service representatives. International Journal of Human Resource Management, 16, 136-160. https://doi.org/10.1080/0958519042000295000

Rothmann, S., Mostert, K., \& Strydom, M. (2006). A psychometric evaluation of the Job Demands-Resources Scale in South Africa. SA Journal of Industrial Psychology 32, 76-86. https://doi.org/10.4102/sajip.v32i4.239

Saks, A. M. (2006). Antecedents and consequences of employee engagement. Journa of Managerial Psychology, 21, 600-619. https://doi.org/10.1108/02683940 610690169

Schaufeli, W. B., \& Bakker, A. B., (2003). UWES Manual. Utrecht, Netherlands: Occupational Health Psychology Unit, Utrecht University.

Schaufeli, W. B., \& Bakker, A. B. (2004). Job demands, job resources and their relationship with burnout and engagement: A multi-sample study. Journal of Organisational Behaviour, 25, 293-315. https://doi.org/10.1002/job.248

Schaufeli, W. B., \& Bakker, A. B. (2010). Defining and measuring work engagement Bringing clarity to the concept. In A. B. Bakker \& M. P. Leiter (Eds.), Work engagement: A handbook of essential theory and research. New York: Psychology Press.

Schaufeli, W. B., \& Enzmann, D. (1998). The burnout companion to study and practice: A critical analysis. London: Taylor \& Francis.

Schaufeli, W. B., \& Taris, T. W. (2014). A critical review of the job demands-resources model: Implications for improving work and health. In G. F. Bauer \& O. Hämmige (Eds.), Bridging occupational, organizational and public health: A transdisciplinary approach, (pp. 43-68). Dordrecht: Springer Science+Business Media. https://doi. org/10.1007/978-94-007-5640-3_4

Schaufeli, W. B., Bakker, A. B., \& Salanova, M. (2006). The measurement of work engagement with a short questionnaire. Educational and Psychological Measurement, 66, 701-716. https://doi.org/10.1177/0013164405282471

Schaufeli, W. B., Leiter, M. P., Maslach, C., \& Jackson, S. E. (1996). MBI-General Survey Palo Alto, CA: Consulting Psychologists Press.

Schaufeli, W. B., Salanova, M., González-Romá, V., \& Bakker, A. B. (2002). The measurement of engagement and burnout: A two sample confirmatory factor analytic approach. Journal of Happiness Studies, 3, 71-92. https://doi.org/ analytic approach. Journal

Schumacker, R. E. \& Lomax, R. G. (2004). A beginner's guide to structural equation modeling (2nd edn.). Mahwah, NJ: Lawrence Erlbaum Associates.

Simpson, M. R. (2008). Engagement at work: A review of the literature. International Journal of Nursing Studies, 45, 1-13.

South African Bureau of Standards (2008). South African national standard: Business process outsourcing and offshoring operations. Part 2: Inbound contact centre operations (1st edn.). SANS 990-2:2008. Pretoria: SABS Standards Division.

Spies, M. (2006). Emotional labour and the experience of emotional exhaustion amongst customer service representatives in a call centre. Unpublished Master's thesis, Stellenbosch, South Africa: University of Stellenbosch.
Storm, K., \& Rothmann, S. (2003). A psychometric analysis of the Maslach Burnout Inventory-General Survey in the South African Police Service. South African Inventory-General Survey in the South African Police Service. South African
Journal of Psychology, 33(4), 219-226. https://doi.org/10.1177/00812463030 3300404

Strydom, A. S. L. (2005). Report on assessing performance management systems in South African call centres. Unpublished Master's thesis, Pretoria, South Africa: University of South Africa.

Swart, J. (2006). The relationship between job characteristics, work wellness and workrelated flow of call centre agents in an insurance company. Unpublished Master's thesis, Potchefstroom, South Africa: University of the North-West.

Tett, R. P., \& Meyer, J. P. (1993). Job satisfaction, organisational commitment, turnove intention and turnover: Path analyses based on meta-analytic findings. Personne Psychology, 46, 259-293. https://doi.org/10.1111/j.1744-6570.1993.tb00874.x

Townsend, K. (2007). Recruitment, training and turnover: Another call centre paradox. Personnel Review, 36, 476-490. https://doi.org/10.1108/00483480710731383

Travaglian, F., Babic, A., \& Hansez, I. (2016). The role of work-related needs in the relationship between job crafting, burnout and engagement. SA Journal of Industrial Psychology/SA Tydskrif vir Bedryfsielkunde, 42(1), a1308. https://doi. org/10.4102/sajip.v42i1.1308

Van den Broek, D. (2003). Recruitment strategies and union exclusion in two Australian call centres. Industrial Relations, 58, 515-535. https://doi.org/10.7202/007497ar

Van der Linde, E. (2005). The relationship between personality traits and work performance of call centre agents. Unpublished Master's thesis, Pretoria, South Africa: University of South Africa.

Visser, W. A., \& Rothmann, S. (2008). Exploring antecedents and consequences of burnout in a call centre. SA Journal of Industrial Psychology, 34, 79-87. https:// doi.org/10.4102/sajip.v34i2.734

Visser, W. A., \& Rothmann, S. (2009). The development of a hassle-based diagnostic scale for predicting burnout in call centres. SA Journal of Human Resource Management, 7, 1-8. https://doi.org/10.4102/sajhrm.v7i1.181

Werbel, J. D., \& Gilliland, S.W. (1999). Person-environment fit in the selection process. In G. R. Ferris (Ed.), Research in personnel and human resource management (pp. 209-243). Stamford, Connecticut: JAI Press.

White, C., \& Roos, V. (2005). Core competencies of a call centre agent. SA Journal of Human Resource Management, 3, 41-47. https://doi.org/10.4102/sajhrm.v3i2.63

Whitt, W. (2006). The impact of increased employee retention on performance in a customer contact center. Manufacturing \& Service Operations Management, 8 235-252. https://doi.org/10.1287/msom.1060.0106

Witham, R. (Ed.) (2009). The South African Contact Centre Human Capital Focus Report. Johannesburg: C3 Africa Research.

World Health Organisation. (2006). Constitution of the World Health Organisation. Basic documents, Forty-fifth edition, Supplement, October 2006. Retrieved from http://www.who.int/governance/en/who_constitution_en.pdf

Yang, L., Che, H., \& Spector, P.E. (2008). Job stress and well-being: An examination from the view of person-environment fit. Journal of Occupational and Organizational Psychology, 81, 567-587. https://doi.org/10.1348/09631790 7X243324

Zapf, D., Isic, A., Bechtoldt, M., \& Blau, P. (2003). What is typical for call centre jobs? Job characteristics, and service interactions in different call centres. European Journal of Work and Organizational Psychology, 12, 311-340. https://doi org/10.1080/13594320344000183 